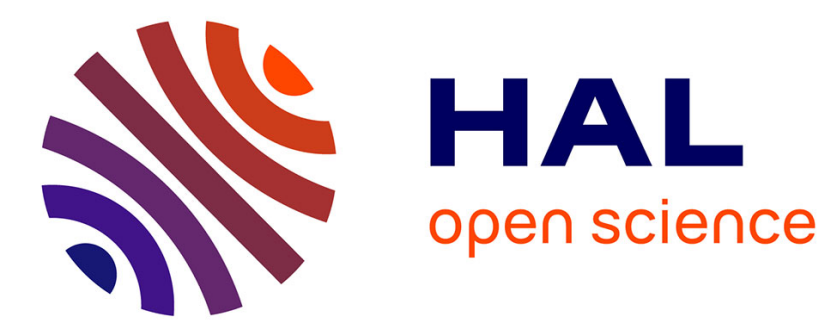

\title{
Diversion of a thioglycoligase for the synthesis of 1-O-acyl arabinofuranoses
}

Quentin Pavic, Sylvain Tranchimand, Loïc Lemiègre, Laurent Legentil

\section{To cite this version:}

Quentin Pavic, Sylvain Tranchimand, Loïc Lemiègre, Laurent Legentil. Diversion of a thioglycoligase for the synthesis of 1-O-acyl arabinofuranoses. Chemical Communications, 2018, 54 (44), pp.55505553. $10.1039 / \mathrm{c} 8 \mathrm{cc} 01726 \mathrm{c}$. hal-01807886

\section{HAL Id: hal-01807886 \\ https://hal-univ-rennes1.archives-ouvertes.fr/hal-01807886}

Submitted on 4 Nov 2021

HAL is a multi-disciplinary open access archive for the deposit and dissemination of scientific research documents, whether they are published or not. The documents may come from teaching and research institutions in France or abroad, or from public or private research centers.
L'archive ouverte pluridisciplinaire HAL, est destinée au dépôt et à la diffusion de documents scientifiques de niveau recherche, publiés ou non, émanant des établissements d'enseignement et de recherche français ou étrangers, des laboratoires publics ou privés. 


\title{
Diversion of a thioglycoligase for the synthesis of 1-O-acyl arabinofuranoses
}

\author{
Quentin Pavic, Sylvain Tranchimand, Loïc Lemiègre and Laurent Legentil \\ Univ Rennes, Ecole Nationale Supérieure de Chimie de Rennes, CNRS, ISCR - UMR 6226, F-35000 \\ Rennes, France.
}

E-mail : laurent.legentil@ensc-rennes.fr

\begin{abstract}
An arabinofuranosylhydrolase from the GH51 family was transformed into an acyl transferase by mutation of the catalytic acid/base amino acid. The resulting enzyme was able to transfer carboxylic acid onto the anomeric position of arabinose with complete chemo- and stereoselectivity. A wide range of acyl $\alpha$-I-arabinofuranoses was obtained with yields ranging from 25 to $83 \%$. Using this method, ibuprofen and N-Boc phenylalanine were successfully transformed into their corresponding acyl conjugates, expanding the scope of the reaction to drugs and amino acids.
\end{abstract}

Glycosyl esters are a family of carbohydrates with increasing potential as bioactive or industrially relevant compounds. Indeed carbohydrates acylated by aryl carboxylic acids, ${ }^{1}$ fatty acids ${ }^{2}$ or saponins ${ }^{3}$ are known high value water soluble preservatives, surfactants or food additives (Stevioside for example). ${ }^{4}$ Such conjugates are naturally present in fruits or vegetables, mainly as 1,2-trans isomers. ${ }^{5,6}$ They constitutes also important metabolites as many xenobiotic carboxylic acids undergo phase II conjugation with glucuronic acid to give the corresponding 1-O-acyl $\beta$-d-glucuronides that are easily excreted through the bile duct or the kidneys. ${ }^{7}$

The lack of stability of glycosyl esters hampers their extractability and their transfer as manufactured fine chemicals is difficult. Different synthetic strategies were therefore implemented to access such useful intermediates starting from either partially protected or unprotected sugar. Most popular methods relied on $\mathrm{S}_{\mathrm{N}} 2$ nucleophilic substitution of glycosyl halides ${ }^{8,9}$ or trichloroacetimidate glycosides, ${ }^{10}$ remote activation of methoxypyridyl glycoside, ${ }^{11}$ Mitsunobu ${ }^{12}$ or carbodiimide-promoted coupling ${ }^{13}$ to yield either $\alpha$ - or $\beta$-glycosyl esters. Such strategies nevertheless lack either efficiency or selectivity. Alternatively, biotechnological tools were developed to access in particular 1-O-acyl glucuronides. They relied on microsomial preparation of UDP-glucuronyltransferases ${ }^{14}$ or the use of lipases ${ }^{15,16}$ as catalyst for the transfer of carboxylic acid to nucleotide- or free sugar respectively. Such seducing approaches are however hampered by either the low availability of the substrate or the lack of versatility of the catalyst.

Very recently, sucrose phosphorylases have been shown to accept carboxylic acids to provide the corresponding 1-O-acyl $\alpha$-d-glucoses. ${ }^{17,18}$ The reaction proceeds smoothly with benzoic or acetic acid but is limited to sucrose as substrate. If such phosphorylase could serve as an acyl transferase, there is a possibility that less specific hydrolases could perform the same task. Glycosylhydrolases in the presence of a large excess of alcohol are known to perform transglycosylation. ${ }^{19}$ However carboxylic acids are poor nucleophiles and the competition with water would be in favor of the latter (Scheme 1). In addition the resulting glycosyl esters are known to be readily hydrolyzed by native glycosylhydrolases. ${ }^{20}$ Interestingly, Withers and co-workers have designed an elegant strategy to favour the attack of various nucleophiles by the mutation of the acid/base residue. ${ }^{21}$ Such mutation 
drastically reduces the kinetic of the attack of water allowing competition with other nucleophiles like mercaptan, ${ }^{22}$ fluoride ${ }^{23}$ and even carboxylic acid. ${ }^{24}$ But for the last two examples, the resulting conjugates were only detected and never isolated. In fact, the thioligases have never been diverted for the synthesis of acyl glycoside derivatives. We thus propose herein a novel strategy for the synthesis of glycosyl esters by the use of a thioligase as innovative and original acyl transfer catalyst.

Scheme 1 Competition between hydrolysis and acylation of the glycosyl-enzyme intermediate upon action of a glycosylhydrolase.
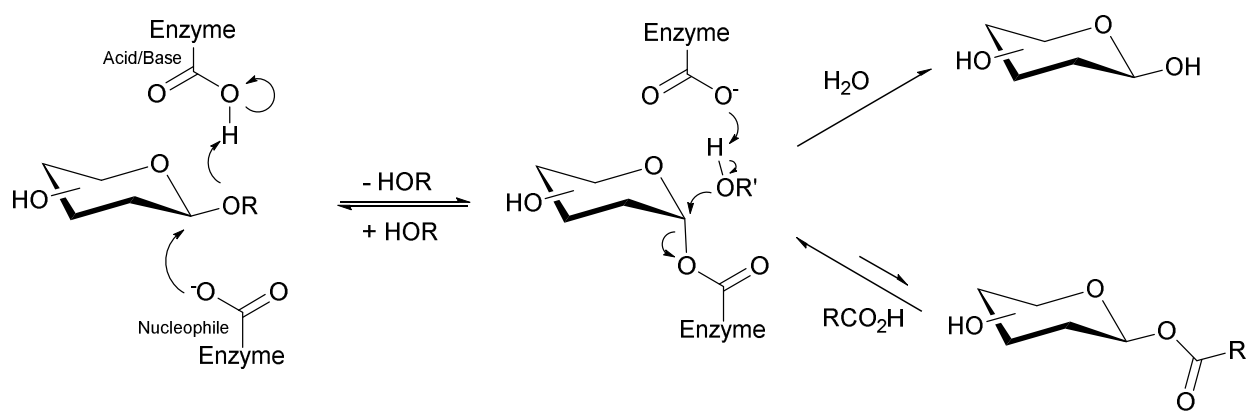

The drawback associated with the monitoring of glycosyl ester formation is their non-stability due to acyl migration. 1,2-trans Acyl arabinofuranoses are known to be more stable and less prone to such rearrangement. ${ }^{25}$ Interestingly Davies and collaborators have reported on a versatile, thermostable hydrolase that efficiently degrades polymers of I-arabinose, the arabinofuranosidase 51 from Rhuminiclostridium thermocellum (CtAraf51). ${ }^{26}$ Latter on Ferrières and co-workers used this enzyme as efficient biocatalyst in both self-condensation and transglycosylation of L-arabinofuranose donor. ${ }^{27,28}$ Furthermore, CtAraf51 was successfully transformed into the corresponding thioligase by the mutation of the glutamic acid 173 into the alanine. The resulting mutant CtAraf51 E173A was able to recognize a thioimidoyl arabinofuranoside 1 as a donor and transfer the furanose to different thiophenol via a remote activation mechanism. ${ }^{29}$ From there, we decided to perform the 1-O-acylation of arabinose from 1 with CtAraf51 E173A as catalyst to provide a wide range of 1-O-acyl arabinofuranoses (Scheme 2).

Scheme 2 Strategy of acylation of L-arabinose by the thioligase CtAraf51 E173A

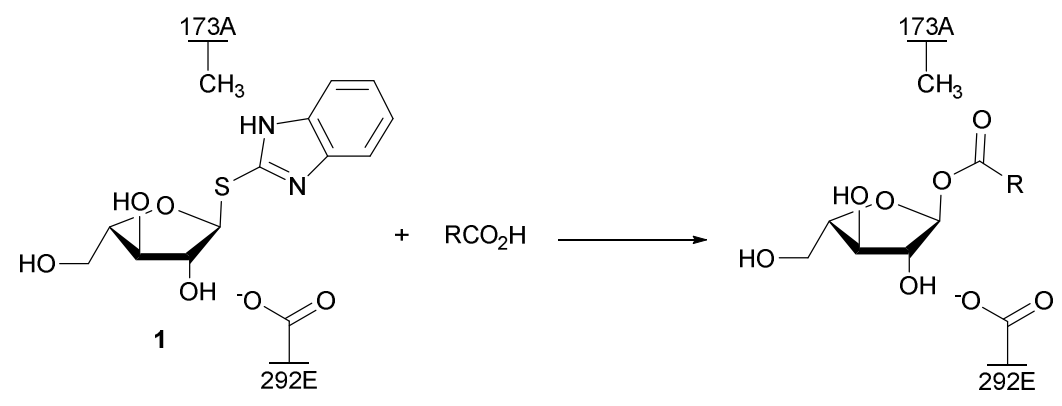

We tested first our strategy starting from $\mathbf{1}^{30}$ and 4-methoxybenzoic acid as the acylating agent (Figure 1). The mutant Araf51 E173A was expressed according to known procedure. ${ }^{29}$ The reaction was performed in $50 \mathrm{mM}$ phosphate buffer $\mathrm{pH} 7$ at $25^{\circ} \mathrm{C}$ in the presence of an excess of 4-methoxybenzoic acid. In the absence of the catalyst, no reaction occurred. Gratifyingly, when Araf51 E173A was added, TLC analysis showed the formation of a new spot identified after purification as the 1-Omethoxybenzoyl $\alpha$-L-arabinofuranose 2 . The isolated yield reached $52 \%$. The structure of $\mathbf{2}$ was 
unambiguously confirmed by NMR spectroscopy. ${ }^{1} \mathrm{H}$ and ${ }^{13} \mathrm{C}$ NMR showed in particular signals at 6.05 $\mathrm{ppm}$ and $102.3 \mathrm{ppm}$ respectively, characteristic of an acylated anomeric position. The associated coupling constant reached $1.1 \mathrm{~Hz}$, typical of a 1,2-trans configuration. Such complete diastereoselectivity of the reaction was expected as the selected furanosidase works with retention of configuration. The resulting 1- $O$-methoxybenzoyl $\alpha$-L-arabinofuranose $\mathbf{2}$ was surprisingly very stable and did not undergo acyl migration or hydrolysis in the course of the reaction unlike others acyl glycosides ${ }^{31}$ (monitored by ${ }^{1} \mathrm{H}$ NMR. See ESI). Interestingly, using the native Araf51 as catalyst, sole the arabinose was formed. These preliminary results validated our model and confirm the possibility to implement a new reactivity, the acylation, to a glycosidase after mutation of the acid/base residue. It also confirmed the crucial role of the mutation to prevent the competition of the carboxylic acid acceptor with water.

Figure 1 Synthesis of 4-methoxybenzoyl $\alpha$-I-arabinofuranose 2 catalysed by CtAraf51 E173A

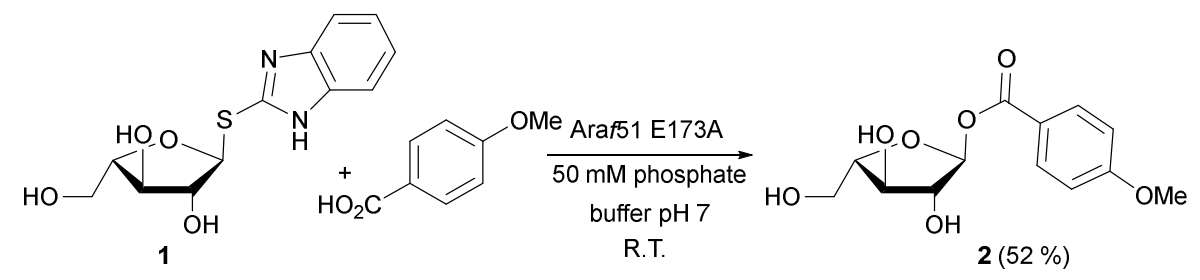

In order to optimize this reaction, different conditions $(\mathrm{pH}$, time, donor/acceptor ratio) were then screened (Table 1). On one hand, at pH below 4.5 (entry 1), the thioimidoyl arabinofuranose 1 was quickly chemically hydrolysed due to proton activation of the benzimidazole. On the other hand, in alkaline conditions, typically the one used for thioligation, no product of acylation could be detected and only the starting thioimidoyl arabinofuranoside $\mathbf{1}$ and arabinose were found (entry 2). Interestingly, improved isolated yield compared to neutral pH was obtained at acidic $\mathrm{pH}$ (entry $3 \mathrm{vs}$. entry 4). Complete disappearance of 1 was achieved after $24 \mathrm{~h}$ and the isolated yield reached $78 \%$ (entry 5). It nevertheless dropped to $60 \%$ when using an equimolar equivalent of 4-methoxybenzoic acid (entry 6). In these conditions the kinetic slowed down and a fair amount of hydrolysis occurred. In addition, using ${ }^{1} \mathrm{H} N M R$, we confirmed that in neutral and alkaline media, the resulting product $\mathbf{2}$ was more sensitive to chemical hydrolysis (See ESI). It correlated the larger amount of arabinose found when the reaction occurred at pH above 6 (entry 4 vs. entries 2 and 3).

Table 1 Screening of $\mathrm{pH}$ and acceptor amount for the acylation of thioimidoyl arabinofuranoside 1 by 4-methoxybenzoic acid. Conditions: CtAraf51 E173A, 50 mM phosphate buffer, R.T.

\begin{tabular}{|l|l|l|l|l|l|}
\hline Entry & $\begin{array}{l}\text { Equivalent } \\
\text { of acceptor }\end{array}$ & $\mathrm{pH}$ & $\begin{array}{l}\text { Time } \\
(\mathrm{h})\end{array}$ & $\begin{array}{l}\text { Yield of } \\
\mathbf{2}(\%)\end{array}$ & $\begin{array}{l}\text { Ratio } \\
\text { Ara/2 }\end{array}$ \\
\hline 1 & 4 & 4.5 & 16 & - & $1 / 0$ \\
\hline 2 & 4 & 8 & 16 & - & $1 / 0^{\mathrm{b}}$ \\
\hline 3 & 4 & 7 & 16 & 52 & $0.3 / 1$ \\
\hline 4 & 4 & 6 & 16 & 67 & $0.1 / 1$ \\
\hline 5 & 4 & 6 & 24 & 78 & $0.15 / 1$ \\
\hline 6 & 1 & 6 & 24 & 60 & $0.4 / 1$ \\
\hline
\end{tabular}

${ }^{a}$ determined by NMR. ${ }^{b}$ in this case large amount of 1 remained. 
In term of mechanism, the reaction should proceed according to the canonical mechanism described by Withers. ${ }^{21}$ The first half-reaction followed a two-steps process i) attack of the nucleophilic residue glutamate 292 and ii) subsequent departure of thiobenzimidazole via a remote activation mechanism ${ }^{29}$ (Scheme 3). The second-half of the reaction, that is to say the attack by the carboxylic acid, can proceed according to two different scenarios with either the carboxylic acid or the carboxylate as the nucleophile. Sugimoto et al. demonstrated that the acylation of glucose catalysed by sucrose phosphorylase proceeded best at $\mathrm{pH}$ below the $\mathrm{pK}_{\mathrm{a}}$ of acetic or benzoic acid meaning that the protonated form of the acid probably act as the nucleophile. ${ }^{17}$ In our case, the difference in efficiency between $\mathrm{pH} 6$ and $\mathrm{pH} 7$ was not striking and it is probably the carboxylate form that act as the nucleophile. Such form does not need to be activated unlike water. As the mutation of the glutamate residue 173 by an alanine one reduced drastically the activation of water, the carboxylate can compete efficiently to give the corresponding acyl 1,2-trans arabinofuranose as the only product of the reaction (Scheme 3).

Scheme 3 Hypothesized mechanism of 1-O-acylation of thioimidoyl arabinofuranoside 1 catalysed by Araf51 E173A.

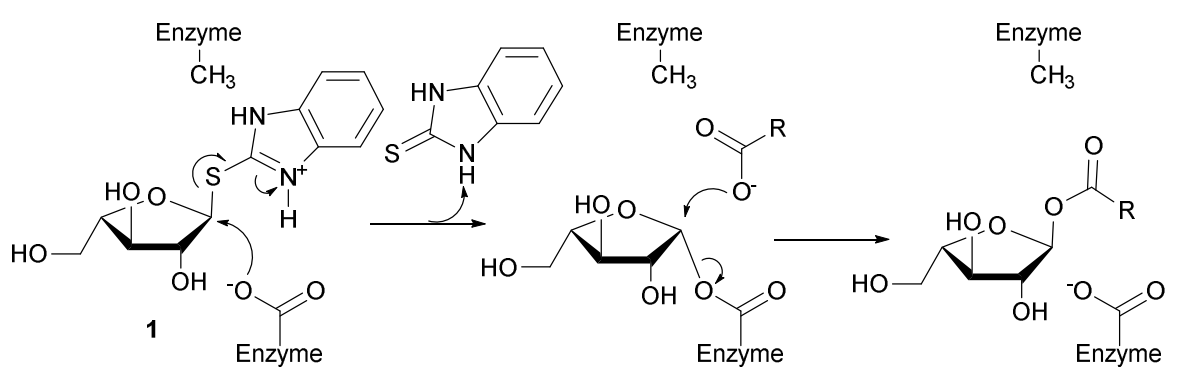

According to our data, the $\mathrm{pH}$ nevertheless influenced greatly the kinetic of the reaction. The Araf51 is known to be stable and active in a large range of $\mathrm{pH}^{26} \mathrm{It}$ is therefore not the potential degradation of the enzyme that can explain such difference. We suspect that the difference in reactivity is linked to the first half-reaction rather than the second-half one. Acidic media could indeed contribute to accelerate the departure of the thiobenzimidazole aglycon thus increasing the turn-over of the reaction.

Finally, to demonstrate the versatility of the reaction, a large panel of carboxylic acid was screened as acceptor of the acylation reaction (Table 2). ${ }^{\ddagger}$ It included aryl and alkyl carboxylic acid as well as amino acids or drugs like ibuprofen. The yields for the furanosylation of aryl carboxylic acid ranged from 18 to $83 \%$ (entries 1 to 5). The lowest yields were found with electron-withdrawing groups on the aromatic ring like bromide, trifluoromethyl or nitro (entries 2 to 4). A follow-up of the reaction between 1 and 4-nitrobenzoic acid was performed and showed the concomitant formation of the corresponding acyl arabinofuranose $\mathbf{2 0}$ and arabinose. We then compared the stability of the resulting conjugates at pH 6 in the presence or the absence of Araf51 E173 (See ESI). A strong increase of the kinetic of hydrolysis was found when the enzyme was added. The presence of the electronwithdrawing group must reduce the nucleophilicity of the carboxylic acid and increase the nucleofuge property of the acyl group of the product. Both effects contributed then to increase the competition with water. The same trend was observed using salicylic acid as substrate (See ESI). The strong hydrolysis observed was probably linked to the activation of the ester function by the phenol in ortho position. Interestingly, the alkyl carboxylic acids 2-phenylacetic acid $\mathbf{1 0}$ and hexanoic acid $\mathbf{1 2}$ were readily converted to the corresponding acyl arabinofuranoses $\mathbf{2 2}$ and $\mathbf{2 3}$ with yields up to $66 \%$ (entries 
6 and 7). For the bulkier pivaloic acid 14, the conversion remained low probably because of the steric hindrance (entry 8). Gratifyingly ibuprofen $\mathbf{1 1}$ was transformed into the acyl conjugate $\mathbf{2 5}$ with an excellent $83 \%$ yield (entry 9) opening the possibility to transfer the methodology to the synthesis of acyl glucuronides that result from phase II metabolism of drugs. It was worth reporting that no stereoselection occurred when using racemic ibuprofen and a 1:1 ratio of diastereoisomers was obtained (See ESI). Also with 6-hydroxyhexanoic acid $\mathbf{1 3}$ no product of $O$-glycosylation was formed and the corresponding acyl arabinofuranose 26 was obtained in $53 \%$ yield (entry 10). The same chemoselectivity was found using hydroxybenzoic acid 7 (entry 5). Even the 4 (mercaptomethyl)benzoic acid $\mathbf{8}$ reacted with $\mathbf{1}$ without formation of the thiobenzyl arabinoside isomer (entry 11). Thus it showed in our conditions that carboxylic acid was a better nucleophile than the phenol, the alcohol or the aliphatic thiol. Finally, no reaction was detected in the presence of 4(aminomethyl)benzoic acid $\mathbf{9}$ (entry 12) or phenylalanine (entry 13). The presence of the ammonium group seemed to be detrimental to the approach of the acceptor in the +1 sub-site. Indeed, when the amine of phenylalanine was protected as a carbamate, the resulting acyl conjugate $\mathbf{3 0}$ was obtained with $38 \%$ yield (entry 14). Such result paves the way to the extension of the scope of reaction in the domain of protein glycosylation.

Table 2 Extension to various carboxylic acid acceptors ${ }^{\ddagger}$
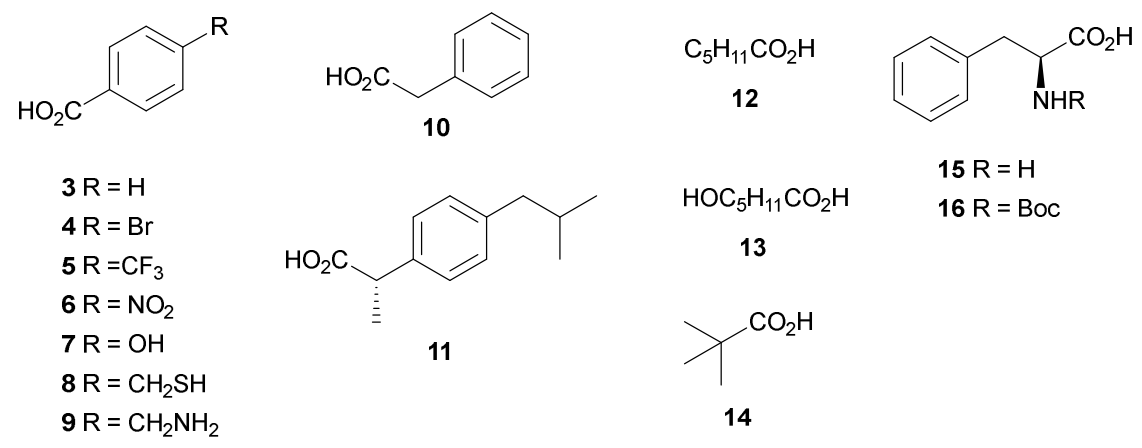

\begin{tabular}{|c|c|c|c|}
\hline Entry & Acceptor $\mathrm{RCO}_{2} \mathrm{H}$ & Isolated Yield (\%) & 1-O-Acyl Araf \\
\hline 1 & $\mathbf{3}$ & 57 & $\mathbf{1 7}$ \\
\hline 2 & $\mathbf{4}$ & 47 & $\mathbf{1 8}$ \\
\hline 3 & $\mathbf{5}$ & 57 & $\mathbf{1 9}$ \\
\hline 4 & $\mathbf{6}$ & $18^{\text {a }}$ & $\mathbf{2 0}$ \\
\hline 5 & $\mathbf{7}$ & 78 & $\mathbf{2 1}$ \\
\hline 6 & $\mathbf{1 0}$ & 66 & $\mathbf{2 2}$ \\
\hline 7 & $\mathbf{1 2}$ & 77 & $\mathbf{2 3}$ \\
\hline 8 & $\mathbf{1 4}$ & 25 & $\mathbf{2 4}$ \\
\hline 9 & $\mathbf{1 1}$ & $83^{\mathrm{a}}$ & $\mathbf{2 5}$ \\
\hline 10 & $\mathbf{1 3}$ & 53 & $\mathbf{2 6}$ \\
\hline 11 & $\mathbf{8}$ & $100^{\mathrm{b}}$ & $\mathbf{2 7}$ \\
\hline 12 & $\mathbf{9}$ & - & $\mathbf{2 8}$ \\
\hline 13 & $\mathbf{1 5}$ & - & $\mathbf{2 9}$ \\
\hline 14 & $\mathbf{1 6}$ & 38 & $\mathbf{3 0}$ \\
\hline
\end{tabular}

${ }^{\mathrm{a}} 1: 1$ ratio of diatereoisomer with $\left( \pm\right.$ ) ibuprofen ${ }^{\mathrm{b}}$ Conversion yield determined by NMR 
To summarize, we report here a novel catalytic pathway for the synthesis of glycosyl esters using a mutated glycosylhydrolase. This methodology has the advantage to use stable reactant and readily available enzyme. It is performed in mild reaction conditions and with a large range of carboxylic acids with good yields and excellent selectivity. This study in particular shows the plasticity of glycosylhydrolases and in particular the arabinofuranosidase towards numerous catalytic activities. In addition to transglycosylation and thioligation, this enzyme is also able to perform acylation of arabinose. Interestingly the reaction could be extended to mimics of L-arabinose, like Dgalactofuranose with potential biological properties. Also the extension of the methodology to thioligases with greater interest like glucuronidase would be a definite advantage for the synthesis of the corresponding acyl glucuronides.

\section{Acknowledgements}

We are grateful to CNRS and the "Ministère de l'enseignement supérieur et de la recherche" for financial supports. We thank the "Centre Regional des Mesures Physiques de l'Ouest (Université de Rennes 1)" for the registration of the mass spectra. This work benefited from the support of the project C-linkAse ANR-15-CE07-0009-01 of the French National Research Agency (ANR).

\section{Conflicts of interest}

There are no conflicts to declare

\section{Notes and references}

¥ General procedure for the enzymatic synthesis of glycosyl esters: A mixture of 4 equivalent of carboxylic acid acceptor in phosphate buffer $(20 \mathrm{~mL}, 50 \mathrm{mM}, \mathrm{pH}=6)$ was prepared and $\mathrm{pH}$ was adjusted to 6 with $\mathrm{NaOH} 2 \mathrm{~N}$. The mutant enzyme Araf51 E173A ( $\approx 5 \mathrm{mg}, 0.00025 \mathrm{eq})$ and 2'-benzimidazolyl-1-thio- $\alpha$ - $L$-arabinofuranoside $1(\approx 100$ $\mathrm{mg}, 0.35 \mathrm{mmol}, 1 \mathrm{eq}$ ) were added. The mixture was stirred at RT for 16 hours. After freeze-drying, the mixture was purified by column chromatography on silica gel to yield the corresponding 1-O-acyl arabinofuranose.

1. B. Baderschneider and P. Winterhalter, J. Agric. Food Chem., 2001, 49, 2788-2798.

2. J.-F. Li, S.-J. Chen, Y. Zhao and J.-X. Li, Carbohydr. Res., 2009, 344, 599-605.

3. I. Podolak, A. Galanty and D. Sobolewska, Phytochem. Rev., 2010, 9, 425-474.

4. S. Ceunen and J. M. C. Geuns, J. Nat. Prod., 2013, 76, 1201-1228.

5. G. R. Pettit, D. E. Schaufel-berger, R. A. Nieman, C. Dufresne and J. A. Saenz-Renauld, J. Nat. Prod., 1990, 53, 1406-1413.

6. T. Okuda, T. Yoshida, M. Ashida and K. Yazaki, J. Chem. Soc., Perkin Trans. 1, 1983, 1765-1772.

7. J. K. Ritter, Chem.-Biol. Interact., 2000, 129, 171-193.

8. S. Feng and C. Li, J. Agric. Food Chem., 2015, 63, 5732-5739.

9. A. Baba and T. Yoshioka, Org. Biomol. Chem., 2006, 4, 3303-3310.

10. J. L. Hixson, Y. Hayasaka, C. D. Curtin, M. A. Sefton and D. K. Taylor, J. Agric. Food Chem., 2016, 64, 9401-9411.

11. S. Hanessian, V. Mascitti, P.-P. Lu and H. Ishida, Synthesis, 2002, 14, 1959-1968.

12. H. Takeuchi, K. Mishiro, Y. Ueda, Y. Fujimori, T. Furuta and T. Kawabata, Angew. Chem. Int. Ed., 2015, 54, 6177-6180.

13. J. A. Perrie, J. R. Harding, D. W. Holt, A. Johnston, P. Meath and A. V. Stachulski, Org. Lett., 2005, 7, 2591-2594.

14. D. Buchheit, C.-A. Drăgan, E. I. Schmitt and M. Bureik, Drug Metab. Disposition, 2011, 39, 2174-2181.

15. D. An, X. Zhao and Z. Ye, Carbohydr. Res., 2015, 414, 32-38.

16. E. Valepyn, J. Nys, A. Richel, P. Laurent, N. Berezina, O. Talon and M. Paquot, Biocatal. Biotransform., 2011, 29, 25-30.

17. K. Sugimoto, K. Nomura, H. Nishiura, K. Ohdan, K. Ohdan, H. Hayashi and T. Kuriki, J. Biosci. Bioeng., 2007, 104, $22-29$.

18. K. Nomura, K. Sugimoto, H. Nishiura, K. Ohdan, T. Nishimura, H. Hayashi and T. Kuriki, Biosci., Biotechnol., Biochem., 2008, 72, 82-87.

19. D. L. Zechel and S. G. Withers, Acc. Chem. Res., 2000, 33, 11-18.

20. T. Kiso, H. Nakano, H. Nakajima, T. Terai, K. Okamoto and S. Kitahata, Biosci., Biotechnol., Biochem., 2000, 64, 1702-1706.

21. M. Jahn, J. Marles, R. A. J. Warren and S. G. Withers, Angew. Chem. Int. Ed., 2003, 42, 352-354.

22. J. Müllegger, H.-M. Chen, W. Y. Chan, S. P. Reid, M. Jahn, R. A. J. Warren, H. M. Salleh and S. G. Withers, ChemBioChem, 2006, 7, 1028-1030.

23. D. L. Zechel, S. P. Reid, O. Nashiru, C. Mayer, D. Stoll, D. L. Jakeman, R. A. J. Warren and S. G. Withers, J. Am. Chem. Soc., 2001, 123, 4350-4351.

24. Q. Wang, D. Trimbur, R. Graham, R. A. J. Warren and S. G. Withers, Biochemistry, 1995, 34, 14554-14562. 
25. S. Tejima and H. G. Fletcher, J. Org. Chem., 1963, 28, 2999-3004.

26. Edward J. Taylor, Nicola L. Smith, Johan P. Turkenburg, S. D'Souza, Harry J. Gilbert and Gideon J. Davies, Biochem. J., 2006, 395, 31-37.

27. I. Chlubnova, B. Kralova, H. Dvorakova, P. Hosek, V. Spiwok, D. Filipp, C. Nugier-Chauvin, R. Daniellou and V. Ferrieres, Org. Biomol. Chem., 2014, 12, 3080-3089.

28. A. Pennec, R. Daniellou, P. Loyer, C. Nugier-Chauvin and V. Ferrières, Carbohydr. Res., 2015, 402, 50-55.

29. M. Almendros, D. Danalev, M. Francois-Heude, P. Loyer, L. Legentil, C. Nugier-Chauvin, R. Daniellou and V. Ferrieres, Org. Biomol. Chem., 2011, 9, 8371-8378.

30. R. Euzen, V. Ferrières and D. Plusquellec, J. Org. Chem., 2005, 70, 847-855.

31. F. Di Meo, M. Steel, P. Nicolas, P. Marquet, J.-L. Duroux and P. Trouillas, J. Mol. Model., 2013, 19, 2423-2432. 